\title{
Transcriptional profiling identifies differentially expressed genes in developing turkey skeletal muscle
}

\author{
Kelly RB Sporer ${ }^{1}$, Robert J Tempelman², Catherine W Ernst ${ }^{2}$, Kent M Reed ${ }^{3}$, Sandra G Velleman ${ }^{4}$, \\ Gale M Strasburg ${ }^{1 *}$
}

\begin{abstract}
Background: Skeletal muscle growth and development from embryo to adult consists of a series of carefully regulated changes in gene expression. Understanding these developmental changes in agriculturally important species is essential to the production of high quality meat products. For example, consumer demand for lean, inexpensive meat products has driven the turkey industry to unprecedented production through intensive genetic selection. However, achievements of increased body weight and muscle mass have been countered by an increased incidence of myopathies and meat quality defects. In a previous study, we developed and validated a turkey skeletal muscle-specific microarray as a tool for functional genomics studies. The goals of the current study were to utilize this microarray to elucidate functional pathways of genes responsible for key events in turkey skeletal muscle development and to compare differences in gene expression between two genetic lines of turkeys. To achieve these goals, skeletal muscle samples were collected at three critical stages in muscle development: 18d embryo (hyperplasia), 1d post-hatch (shift from myoblast-mediated growth to satellite cell-modulated growth by hypertrophy), and 16wk (market age) from two genetic lines: a randombred control line (RBC2) maintained without selection pressure, and a line (F) selected from the RBC2 line for increased 16wk body weight. Array hybridizations were performed in two experiments: Experiment 1 directly compared the developmental stages within genetic line, while Experiment 2 directly compared the two lines within each developmental stage.
\end{abstract}

Results: A total of 3474 genes were differentially expressed (false discovery rate; FDR $<0.001$ ) by overall effect of development, while 16 genes were differentially expressed (FDR $<0.10$ ) by overall effect of genetic line. Ingenuity Pathways Analysis was used to group annotated genes into networks, functions, and canonical pathways. The expression of 28 genes involved in extracellular matrix regulation, cell death/apoptosis, and calcium signaling/ muscle function, as well as genes with miscellaneous function was confirmed by qPCR.

Conclusions: The current study identified gene pathways and uncovered novel genes important in turkey muscle growth and development. Future experiments will focus further on several of these candidate genes and the expression and mechanism of action of their protein products.

\section{Background}

Hyperplasia and hypertrophy are key processes in myogenesis in the domestic turkey. It is well established that the number of muscle fibers is determined embryonically [1], as myoblasts, originating as somites, migrate to the appropriate site of muscle formation, then

\footnotetext{
* Correspondence: stragale@msu.edu

'Department of Food Science and Human Nutrition, Michigan State

University, East Lansing, Michigan, 48824, USA Full list of author information is available at the end of the article
}

proliferate during the process of hyperplasia. These myoblasts then withdraw from the cell cycle, fuse to form multi-nucleated myotubes, and differentiate with commencement of muscle-specific protein expression. After the actual number of muscle fibers is determined during hyperplasia, skeletal muscle stem cells, satellite cells located beneath the basal lamina of the muscle fibers, are activated and fuse with muscle fibers to contribute their nuclei, resulting in a further increase in DNA that directly leads to an increase in protein
C Biomed Central 
synthesis. This post-hatch increase in muscle fiber size (hypertrophy) is responsible for the majority of overall muscle mass accretion $[2,3]$.

All of these events are precisely temporally and spatially regulated by transcription factors, growth factors, and interactions with the extracellular matrix (ECM). The transcription factors Pax3 and Pax7 are responsible early on for determination of cells entering the myogenic program as well as the activation and survival of satellite cells [4,5]. Myogenic regulatory factors (MRFs), including the four basic helix-loop-helix transcription factors Myf5, myogenin, MRF4, and MyoD, are pivotal in regulating genes involved with commitment of proliferating somatic cells to the myogenic lineage and subsequent differentiation [6]. Myocyte enhancer factors (MEFs) comprise another group of transcription factors that work in conjunction with the MRFs to ensure appropriate expression of muscle-specific proteins during differentiation. Binding sites for MEF2s have been discovered in the promoters of many crucial skeletal muscle structural genes [7]. These groups of transcription factors also regulate each other [6,7]. Furthermore, the activation, proliferation, and differentiation of satellite cells are regulated by various growth factors, including insulin-like growth factors (IGF), fibroblast growth factor 2 (FGF2), platelet-derived growth factors (PDGF), hepatocyte growth factors, (HGF), epidermal growth factors (EGF), and transforming growth factor $-\beta$ (TGF- $\beta$ ) [8]. Satellite cell response to the growth factors IGF and FGF2 is different between fast-growing and slow-growing breeds of domestic turkeys [9].

A genetic model has been developed and maintained to study the effects of growth selection in turkeys. This model consists of two lines: a randomly bred control line of turkeys (RBC2), maintained without selection pressure and representing a commercial turkey from 1967 [10], and a unique line genetically derived from the RBC2 birds and selected for over 40 generations solely for 16-wk body weight (F) [11]. The F line turkeys gain body weight faster and yield significantly heavier breast muscles than the RBC2 birds [12]. In addition, satellite cells from $\mathrm{F}$ turkeys have higher proliferation and differentiation rates than those from RBC2 turkeys [13]. Growth comparisons between these two lines are not confounded by selection for other characteristics such as disease resistance, reproductive efficiency, or behavioral traits, as are commercial turkeys.

Many gene expression differences between these two lines have been identified in vitro using isolated satellite cells. The MRFs MyoD and myogenin are differentially expressed between F and RBC2 lines in embryonic pectoralis major muscle and cultured satellite cells [14]. In addition, proteoglycans in the extracellular matrix that interact with growth factors important for proliferation and differentiation of satellite cells exhibit differential expression between the two lines $[15,16]$. These cell culture studies have been pivotal for understanding how satellite cells contribute to muscle growth.

To build on this work, we developed a microarray approach that enabled the simultaneous analysis of skeletal muscle gene transcripts at specific time points in vivo. Previously, our group created and characterized a skeletal muscle-specific microarray, the Turkey Skeletal Muscle Long Oligonucleotide (TSKMLO) array, with the purpose of screening the skeletal muscle transcriptome for candidate genes critical in growth, proliferation, differentiation, and overall development $[17,18]$. Briefly, cDNA libraries were constructed and sequenced using turkey Pectoralis major muscle collected at three stages crucial to development. From these libraries, oligonucleotides representing 5257 putative transcripts as well as oligonucleotides representing unique sequences to control for nonspecific hybridization and template quality were designed and spotted, resulting in the $6 \mathrm{~K}$ skeletal muscle-specific oligonucleotide microarray. Assessment of this platform using dye-swap experiments, evaluation of control probe signals, and qPCR validation of results established this array as a valid and valuable tool for functional genomics studies. The aims of the current study were to utilize this microarray to elucidate functional pathways of genes responsible for key events in turkey skeletal muscle development and to identify differences in temporal gene expression between two genetic lines.

\section{Methods}

\section{Animals and Tissue Collection}

Animals used in this study were domestic turkeys maintained at the Poultry Research Center at The Ohio Agricultural Research and Development Center located in Wooster, OH under AGACUC protocol \#04-AG007. These turkeys were from two genetic lines: $\mathrm{RBC} 2$, a randomly bred control line representative of a 1967 commercial turkey $[10,19]$, and F, a subline genetically selected from the RBC2 line for increased 16wk body weight [11]. The birds were euthanized immediately prior to tissue harvest at one of three developmental stages: $18 \mathrm{~d}$ embryo (18de; hyperplasia), $1 \mathrm{~d}$ post hatch (1d; shift from myoblast-mediated growth to satellite cell modulated growth by hypertrophy), and 16 wk old birds (16wk; approximate age of commercial slaughter). Pectoralis major muscle was excised [17], snap frozen in liquid nitrogen, and stored at $-80^{\circ} \mathrm{C}$ until shipment on dry ice to Michigan State University (MSU), where samples were stored at $-80^{\circ} \mathrm{C}$ until RNA extraction.

\section{RNA Extraction}

Total RNA was isolated from skeletal muscle tissue using TRIReagent (Molecular Research Center, Inc., 
Cincinnati, $\mathrm{OH}$ ) as per manufacturer instructions. All samples were treated with DNA-free ${ }^{\mathrm{TM}}$ DNase (Ambion, Inc., Austin, TX) to remove any contaminating genomic DNA. Sample integrity was confirmed using an Agilent 2100 Bioanalyzer (Santa Clara, CA) that determined RNA Integrity Number (RIN). All samples used for microarray analysis had an RIN > 8.0.

\section{Microarray Experimental Design}

The TSKLMO array was designed and created based on sequences from cDNA libraries constructed at crucial stages in muscle development [18]. Description of this platform can be found on the National Center for Biotechnology Information (NCBI) Gene Expression Omnibus (GEO) database [GEO: GPL9788]. Experiment 1 (Additional File 1, Figure S1a) was designed to directly compare the three developmental stages, $18 \mathrm{de}$ vs. $1 \mathrm{~d}$ or $1 \mathrm{~d}$ vs. $16 \mathrm{wk}$, for each of the genetic lines. Experiment 2 (Additional File 1, Figure S1b) was designed to directly compare the two genetic lines, F vs. RBC2, at each of the developmental stages. Each Experiment contained 10 arrays per comparison; therefore, Experiment 1 contained 40 arrays, and Experiment 2 contained 30 arrays. Birds were randomly assigned to array, and hybridizations were performed in random order.

\section{RNA Amplification and Microarray Hybridization}

Total RNA for microarray analysis was amplified and dye-coupled in preparation for hybridization using the Amino Allyl MessageAmp ${ }^{\mathrm{TM}}$ II aRNA Amplification Kit (Ambion, Inc.) per manufacturer instructions. All microarray preparation and hybridization procedures were performed as previously described [17]. Briefly, all microarrays were UV-crosslinked and pre-hybridized prior to hybridization. Fragmented, Cy3-coupled aRNA was mixed with its Cy5-coupled partner, and the mixtures were hybridized to oligonucleotide microarrays for $18 \mathrm{~h}$ in a GeneTac Hybridization Station (Genomic Solutions, Ann Arbor, MI). Arrays were then rinsed, dried by centrifugation, and immediately scanned with a GenePix 4000B scanner (Molecular Devices, Sunnyvale, CA). Image analysis was performed using GenePix Pro 6.0 software, and spot intensities were exported as GPR files for statistical analysis. Fluorescence intensity data were not background-corrected in accordance with recent recommendations $[20,21]$ but were normalized for dye intensity bias using the LOESS procedure of the normalizeWithinArray function of the Bioconductor $\mathrm{R}$ software LIMMA [22].

\section{Statistical Analysis}

The two sets of experiments were analyzed separately. For the first experiment, in which 1d was directly compared against the other two stages within arrays and within lines, all microarray data were expressed as $\log _{2}$ ratios of each stage with $1 \mathrm{~d}$ for each array. These $\log _{2}$ ratios were analyzed using a linear mixed model based on an overall intercept, the effect of dye assignment for samples deriving from stage $1 \mathrm{~d}$, effects of the other two stages specified as numerator terms in the $\log _{2}$ ratios, effect of line, and the random effects of the animal assigned to stage $1 \mathrm{~d}$ and its interaction with the other two stages to serve as the experimental error term for stage as each oligonucleotide was spotted twice on an array. For this experiment, the comparisons of interest included all stages against each other within each of the two lines, as well as overall differences between the three stages.

For the second experiment, in which lines were compared directly against each other within arrays and within stages, all data were expressed as $\log _{2}$ ratios of $\mathrm{F}$ over RBC2 for each array. These $\log _{2}$ ratios were analyzed using a linear mixed model based on an overall intercept, the dye assignment for samples deriving from line $\mathrm{RBC} 2$, stage effects, the effect of line, and the random effect of the animal derived from the RBC2 line. The random effect could have been also arbitrarily chosen as the animal derived from the $F$ line, but, in either case, this specification ensured that replication was based on the number of animals and not on the number of spots per gene per array. In this experiment, the comparisons of interest were overall line differences and line differences within each stage. SAS PROC MIXED was used for both analyses given the linear mixed model specifications for both experiments [23]. Statistical significance was based on the estimated false discovery rates (FDR) [24].

Raw Cy5 intensities, raw Cy3 intensities, LOESS-normalized $\log _{2}$ Cy5:Cy3 ratios, and LOESS-normalized $\log _{2}$ average intensities (A), as well as original GPR files for all arrays, were submitted to the National Center for Biotechnology Information (NCBI)'s Gene Expression Omnibus (GEO) [GSE19585]. Control probes were also evaluated for both Experiments 1 and 2. Results examining the fluorescence intensities of probes designed to contain an increasing number of mismatched bases as well as scrambled sequence oligos that served as negative controls indicated that hybridization was specific in these experiments. These data have been previously presented [17].

\section{Gene annotation and functional analysis}

After statistical analysis, genes were sorted by FDR, and the top 200 genes differentially expressed by overall effect of development (Experiment 1) and all genes differentially expressed by overall effect of genetic line (Experiment 2) were investigated by subjecting oligonucleotide sequences to an NCBI BLAST search and choosing best matches for accession number and 
putative annotation. In addition, the top 30 up-regulated and down-regulated genes in Experiment 1 and all differentially expressed genes in Experiment 2 in each comparison: F 18de:1d, F 1d:16wk, RBC2 18de:1d, and RBC2 1d:16wk were annotated in the same manner. These lists were then probed for patterns in expression using the Ingenuity Pathways Analysis software (IPA; Redwood City, CA).

\section{Quantitative real-time PCR confirmation}

Twenty-eight genes were chosen by function of interest and high differential expression by microarray analysis for confirmation of those results by quantitative realtime PCR (qPCR). Primers (Table 1) were designed using Primer Express 3.0 software (Applied Biosystems, Foster City, CA) and synthesized by Operon Inc. (Huntsville, AL). Sample RNAs $(2 \mu \mathrm{g})$ were reverse transcribed to cDNA using Superscript III (Invitrogen, Carlsbad, CA) and quantified with a Nanodrop ND1000 spectrophotometer (Thermo Fisher Scientific, Inc., Wilmington, DE). Reactions were run using $10 \mathrm{ng}$ cDNA, 300 nM primer mix, and POWR SYBR Green Master Mix in a 7700 thermocycler system (Applied Biosystems). Data were analyzed by the $2^{-\Delta \Delta \mathrm{Ct}}$ method [25] using hypoxanthine phosphoribosyltransferase (HPRT) as a reference gene and the RBC2, 18de stage as the calibrator; i.e., RBC2, 18de expression is set to "1.0," and all other results are shown as a fold change relative to this control. Statistical analysis was performed using a mixed model and Tukey-Kramer test (SAS, Cary, NC).

\section{Results}

Differential expression of skeletal muscle genes

In Experiment 1, a total of 3474 genes were differentially expressed between at least two developmental stages across both genetic lines (FDR $<0.001$; Table 2). Of these, 2544 genes were significantly affected for the RBC2 birds, whereas 2248 were significantly affected for the $\mathrm{F}$ birds (Table 2). A greater number of genes were up-regulated in the earlier developmental stage of direct comparisons (i.e., $18 \mathrm{de}$ in the $18 \mathrm{de} 1 \mathrm{~d}$ comparison or $1 \mathrm{~d}$ in the $1 \mathrm{~d}: 16$ wk comparison) as compared to those that were down-regulated, and this observation was more pronounced in the $\mathrm{RBC} 2$ line than the $\mathrm{F}$ line. The top 30 down- and up-regulated genes in each comparison are listed in Additional File 2, Table S1. A much smaller number of genes were significantly affected by genetic line in Experiment 2 (Table 2). Only 16 genes were differentially expressed by overall effect of line at an FDR $<0.10$. When considering the effect of line within each developmental stage rather than overall effect across stages, the highest number of genes (63) were affected at the 18de developmental stage (RBC2:F; 39 up-regulated, 24 down-regulated). At $1 \mathrm{~d}$ post-hatch, 20 genes were differentially expressed (5 up, 10 down), and at $16 w k, 8$ genes were differentially expressed (4 up, 4 down). The annotations for these genes are detailed in Additional File 3, Table S2.

\section{Functional and pathway analysis}

After differentially expressed oligos on the TSKMLO array were annotated, lists of accession numbers were subjected to IPA analysis, and Networks (which involve regulatory relationships), Functions (which involve biological and disease processes), and Canonical Pathways (which involve well-characterized cell signaling and metabolic pathways) were considered when investigating functional groups of genes differentially expressed in turkey skeletal muscle during development. These results for Experiment 1 are shown separately for the $\mathrm{RBC} 2$ line and for the $\mathrm{F}$ line (Table 3). Experiment 2 results are shown in Table 4; developmental stages were grouped together because of the small number of differentially expressed genes.

\section{qPCR confirmation of differentially expressed genes}

Genes in the categories of ECM function, cell death, and skeletal muscle development and function, along with several genes with miscellaneous functions, were selected for $\mathrm{qPCR}$ confirmation of microarray results. In addition, genes common to both Experiments 1 and 2 were selected for confirmation.

Figure 1 shows results for versican (1A), glypican-1 (1B), syndecan-4 (1C), spondin 2 (1D), fibroblast growth factor 2 (FGF2; 1E), and collagen VI $\alpha 1$ (COL6A1; 1F), which are all involved in ECM regulation. The COL6A1 gene was also common between Experiments 1 and 2 . Versican and glypican-1 appeared to be expressed predominantly at the $18 \mathrm{de}$ stage when compared to later stages in development. Interestingly, spondin 2 was expressed almost exclusively at the 1d stage, during muscle hypertrophy. Several differences between the RBC2 and F lines were observed by qPCR analysis that were not detected with the significance threshold used for the microarray analysis. Most notably, FGF2 expression at the 18de stage was twice as high in the RBC2 line compared to that of the F line and nearly 3 times greater at the $1 \mathrm{~d}$ stage in the $\mathrm{RBC} 2$ line compared to that of the $\mathrm{F}$ line.

Figure 2 shows results for genes involved in cell death/ apoptosis as determined by IPA: caspase-3 (2A), growth arrest-specific 2 (GAS2; 2B), death-associated protein (DAP; 2C), $\beta$-parvin (2D), platelet-derived growth factor $\alpha$ (PDGF $\alpha$; 2E), nestin (2F), matrix $\gamma$-carboxyglutamic acid (GLA) protein (MGP; 2G), and gelsolin ( $2 \mathrm{H})$. The gene $\beta$-parvin was also common to both Experiments 1 and 2. Caspase-3, GAS2, DAP, and $\beta$-parvin all appeared to be down-regulated as muscle develops. Nestin was 
Table 1 Primer information for genes selected for confirmation by qPCR

\begin{tabular}{|c|c|c|c|c|c|}
\hline Gene & $\begin{array}{l}\text { GenBank } \\
\text { Accession \# }\end{array}$ & Forward primer $\left(5^{\prime} \rightarrow 3^{\prime}\right)$ & Reverse primer $\left(5^{\prime} \rightarrow 3^{\prime}\right)$ & $\begin{array}{l}\text { Amplicon } \\
\text { length, } \\
\text { bp }\end{array}$ & $\begin{array}{l}\mathrm{Tm}, \\
{ }^{\circ} \mathrm{C}\end{array}$ \\
\hline Activin IIB Receptor & NM_204317 & GAGGAGCGCATTGCTCAGAT & GACAAGGCAGTCCGAGGTAGTG & 60 & 83 \\
\hline Beta parvin & XM_416459 & CCAGTCCATACAACTCGCCTIT & CTGTGGTAATACAGCTCACTGGATCT & 71 & 77 \\
\hline BTB domain containing 11 & XM_001234770 & TCTCAAGATGCTGATITCTGTITGT & GTATCGACACATCACTAGAGGAAAGATC & 74 & 75 \\
\hline Calmodulin 1 & NM_001110364 & GGCTGGATACACTTGGTGCAT & GGATCTGATGACCCAGGAAGTT & 68 & 80 \\
\hline Calreticulin & AY393845 & CGCCCTGACAACACCTATGA & CTCCAGGCTCCCCGATTC & 63 & 82 \\
\hline Caspase 3 & NM_204725 & GGAACACGCCAGGAAACTTG & TCTGCCACTCTGCGATTTACA & 63 & 78 \\
\hline Collagen, type VI, alpha 1 (COLGA1) & NM_205107 & TTCCATTGGTGCTCTTGCTATG & TTTGGGATGATGGCGATACC & 79 & 78 \\
\hline Death-associated Protein (DAP) & NM_001031003 & TGGGCAGCTCTACTCTATGTGTTC & CAAGAGCAGTTGTTTCTAACTCAAAAG & 79 & 78 \\
\hline Fibroblast growth factor 2 (FGF2) & NM_205433 & CAATCAAAGGCGTAAGTGCAAA & GCCAGCAATCTGCCATCCT & 61 & 80 \\
\hline Gelsolin & NM_204934 & GCTTACCCCCCTCGTCTITT & TGAGTCAGATCTCCAGGGACTTC & 80 & 80 \\
\hline Glypican-1 & AY551002 & CCAGAGGTGGAGGTGGACAT & TCATGATCTTCAGCTGCATGATT & 73 & 80 \\
\hline Growth Arrest-Specific 2 (GAS2) & XM_420902 & TGATCCTITCTGTTCCTGACAAAG & GGGAGAGGAAAAGGCAACCT & 75 & 80 \\
\hline $\begin{array}{l}\text { Hypoxanthine } \\
\text { phosphoribosyltransferase } 1 \text { (HPRT) }\end{array}$ & NM_204848 & CACAAGAAGCAGCCAGTTACAGTATC & CCCAGATTCCTIITTACAGCAATAA & 92 & 80 \\
\hline Matrix Gla protein (MGP) & NM_205044 & GCACAATGCGTGCTCTCATC & AGCGGCCATGACCAAGAC & 56 & 84 \\
\hline Met proto-oncogene & NM_205212 & CAACAATCTTCTCCACTTTCATTGG & ATAGGGAGCAACACACTTCACGTT & 83 & 77 \\
\hline Myostatin & AF019625 & CACCTGGTACACCAAGCAAATC & TTGGTGGGTGTGCAGCAA & 59 & 83 \\
\hline $\begin{array}{l}\text { Nebulin-related anchoring protein } \\
\text { (NRAP) }\end{array}$ & XM_002194458 & GGCGTACCTTCGGGAAATG & GCAGAATTTCCGAAGCATCAG & 122 & 82 \\
\hline Nestin & NM_205033 & GCCCCGCGACAATCG & TGTTACAAACCAAAGGGAAATGG & 71 & 83 \\
\hline 5'-nucleotidase, cytosolic III (NT5C3) & NM_204436 & TGTGGAGTGGGAAAGTCATACTGTT & CCTGTTGGTAAGAGGTTGAGAAACT & 77 & 77 \\
\hline Plastin 3 & NM_001006431 & TGCTGAGGGCACAGCTACAC & CAACTGAACCAAGATGCATACAAAA & 67 & 78 \\
\hline $\begin{array}{l}\text { Platelet-derived growth factor } A \\
\text { (PDGFA) }\end{array}$ & AB031021 & TGCAACACCAGCAGTGTGAA & TITGCCACCTTGACACTTCTGT & 65 & 81 \\
\hline $\begin{array}{l}\text { Q3_Reed_1DPH_CDNA_08_B09_130 } \\
\text { (Unknown) }\end{array}$ & EH286878 & CCCTGTGCTCATCCTATAAAGCA & CCACGATGCAGCAGGTGAT & 61 & 82 \\
\hline Spondin 2 & XM_420847 & CGTITTGTAGTTCTTCACCCTGCTA & TCACATTCTGTTTCTTCTTCCAGACT & 71 & 77 \\
\hline Syndecan-4 & AY852251 & GCCAACAGCAGCATCTITGA & CAACTGCTCCTCCTGCAATG & 64 & 79 \\
\hline Troponin C type 1 (slow) (TNNC1) & NM_205133 & AGATGGACAGCCCGAATCTCT & TGGGACCAAGGAGCTGATG & 60 & 82 \\
\hline $\begin{array}{l}\text { Troponin I type } 1 \text { (skeletal, slow) } \\
\text { (TNNI1) }\end{array}$ & XM_419242 & TCTGCCCTCTITGCACCATT & GTTGTCCACGTGGTTCATCTCA & 58 & 82 \\
\hline Troponin T type 2 (cardiac)(TNNT2) & NM_205449 & GGCTCAGCCATCAGATGCA & CAGCAGAGCCCTGGCATAG & 54 & 85 \\
\hline $\begin{array}{l}\text { Troponin T type } 3 \text { (skeletal, fast) } \\
\text { (TNNT3) }\end{array}$ & NM_204922 & CCCGTGCCTCAGTGATAACTAAA & AGAAGAAAAGCAGCAGCAATAGC & 68 & 78 \\
\hline Versican & NM_204787 & CAGGATCATTTGTTTGCGGTTA & TCCTGATTCTTCCGCAAGTCA & 60 & 80 \\
\hline
\end{tabular}

highly expressed at the 18 de stage with greater than 100 times the expression of subsequent developmental stages. The MGP gene, however, was expressed principally at the $1 \mathrm{~d}$ stage at 80.28 and 55.38 times the $18 \mathrm{de}$ expression in $\mathrm{RBC} 2$ and F lines, respectively. Gelsolin expression appeared to increase with muscle maturation and peak at the 16 wk time point.

Genes important to skeletal muscle growth and development and calcium signaling are shown in Figure 3. These are myostatin (3A), Activin IIB receptor (ActIIBR; $3 \mathrm{~B})$, calmodulin (3C), calreticulin (3D), and isotypes of troponin: TNNC1 (3E), TNNI1 (3F), TNNT2 (3G), and TNNT3 (3H). Myostatin expression dipped at 1d posthatch, when hypertrophy occurs in muscle; interestingly, its expression was higher in the RBC2 line at $18 \mathrm{de}$ but was higher in the $\mathrm{F}$ line by $16 \mathrm{wk}$ of development. In conjunction, the myostatin receptor ActIIBR was highly down-regulated at 16wk (18de expression was 18.69 and 10.95 times greater in RBC2 and F lines, respectively), when myostatin expression is high. Relative calmodulin and calreticulin expression tended to respond in opposite directions with calmodulin expression highest at the 16 wk stage and calreticulin highest at 18de and decreasing as muscle matures. Of the troponins, TNNI1 and TNNT2 exhibited similar profiles with predominant expression at $18 \mathrm{de}$ that decreased substantially at the other stages. Interestingly, TNNT3 expression appeared to be regulated in the opposite direction of TNNT2.

The expression profiles of several other genes that were common to both Experiments 1 and 2 but did not 
Table 2 Breakdown of differentially expressed genes as affected by skeletal muscle development (Experiment 1) and by turkey genetic line (Experiment 2)

\begin{tabular}{|c|c|c|c|}
\hline Experiment 1 & Overall effect & & \\
\hline FDR $<0.001$ & 3474 & & \\
\hline $\mathrm{RBC2}$ & 18de:1d & 1d:16wk & Total \\
\hline Up & 586 & 1066 & 1652 \\
\hline Down & 463 & 429 & 892 \\
\hline$\underline{\text { Total }}$ & 1049 & 1495 & \\
\hline $\mathrm{F}$ & 18de:1d & 1d:16wk & Total \\
\hline Up & 455 & 746 & 1201 \\
\hline Down & 345 & 702 & 1047 \\
\hline$\underline{\text { Total }}$ & 800 & 1448 & \\
\hline Experiment 2 & Overall effect & & \\
\hline FDR $<0.10$ & 16 & & \\
\hline 18de & $\mathrm{RBC2}: \mathrm{F}$ & & \\
\hline Up & 39 & & \\
\hline Down & 24 & & \\
\hline$\underline{\text { Total }}$ & 63 & & \\
\hline $1 d$ & $\mathrm{RBC2}: \mathrm{F}$ & & \\
\hline Up & 5 & & \\
\hline Down & 15 & & \\
\hline$\underline{\text { Total }}$ & 20 & & \\
\hline $16 w k$ & $\mathrm{RBC2}: \mathrm{F}$ & & \\
\hline Up & 4 & & \\
\hline Down & 4 & & \\
\hline Total & 8 & & \\
\hline
\end{tabular}

easily fall into a functional category, along with one gene with unknown function, are shown in Figure 4. These genes included: BTBD11 (4A), cMet (4B), plastin3 (4C), 5'-nucleotidase, cytosolic III (NT5C3; 4D), and nebulin-related anchoring protein (NRAP; $4 \mathrm{E})$. In addition, a gene with no known annotation was chosen from the top 40 genes differentially expressed by overall effect of development $\left(\mathrm{FDR}<1.0 \times 10^{-13}\right)$ and was subsequently coded Unknown (4F). Expression of these genes was variable although line differences were observed at $1 \mathrm{~d}$ for all genes. Expression of NRAP was dramatically upregulated at $1 \mathrm{~d}$ and $16 \mathrm{wk}$ when compared to $18 \mathrm{de}$. Expression profiles for these 28 genes confirmed that microarray results were repeatable.

\section{Discussion}

Muscle growth and development from the embryonic to the adult stage of an organism consists of a series of exquisitely regulated and orchestrated changes in expression of genes leading to muscle maturation. Genetic selection for body weight and muscle mass is ultimately based on differential expression of genes, and this approach has resulted in dramatic improvements in turkey growth rate, breast muscle mass, and feed efficiency. However, selection for these performance traits has inadvertently led to other undesirable traits including myopathies [26,27], cardiomyopathies [28,29], skeletal deficiencies $[11,30]$, and meat quality defects such as

Table 3 Top five Networks, Functions, and Canonical Pathways from IPA analysis for Experiment 1 for RBC2 and F lines

\begin{tabular}{|c|c|c|}
\hline & $\mathrm{RBC2}$ & $\mathbf{F}$ \\
\hline \multirow[t]{5}{*}{ Networks } & $\begin{array}{c}\text { Tissue Development, Cellular Growth and Proliferation, Skeletal and } \\
\text { Muscular System Development and Function }\end{array}$ & $\begin{array}{c}\text { Tissue Development, Skeletal and Muscular System } \\
\text { Development and Function, Tissue Morphology }\end{array}$ \\
\hline & Genetic Disorder, Skeletal and Muscular Disorders, Gene Expression & Cellular Development, Cell Cycle, Gene Expression \\
\hline & Cancer, Cell Death, Cellular Assembly and Organization & Cell Cycle, Infectious Disease, Inflammatory Disease \\
\hline & $\begin{array}{l}\text { Gene Expression, Cellular Growth and Proliferation, Endocrine System } \\
\text { Development and Function }\end{array}$ & $\begin{array}{l}\text { Cellular Development, Cellular Growth and Proliferation, } \\
\text { Respiratory System Development and Function }\end{array}$ \\
\hline & $\begin{array}{c}\text { Cell-To-Cell Signaling and Interaction, Cellular Growth and } \\
\text { Proliferation, Cancer }\end{array}$ & $\begin{array}{c}\text { Connective Tissue Development and Function, Organismal } \\
\text { Development, Skeletal and Muscular System Development and } \\
\text { Function }\end{array}$ \\
\hline \multirow[t]{5}{*}{ Functions } & Genetic Disorder & Cancer \\
\hline & Skeletal and Muscular Disorders & Skeletal and Muscular System Development and Function \\
\hline & Cardiovascular System Development and Function & Tissue Morphology \\
\hline & Skeletal and Muscular System Development and Function & Tissue Development \\
\hline & Tissue Development & Small Molecule Biochemistry \\
\hline \multirow{5}{*}{$\begin{array}{l}\text { Canonical } \\
\text { Pathways }\end{array}$} & Calcium Signaling & Calcium Signaling \\
\hline & Hepatic Fibrosis/Hepatic Stellate Cell Activation & Glycolysis/Gluconeogenesis \\
\hline & Methionine Metabolism & Urea Cycle and Metabolism of Amino Groups \\
\hline & Pyruvate Metabolism & Tight Junction Signaling \\
\hline & Tight Junction Signaling & Arginine and Proline Metabolism \\
\hline
\end{tabular}


Table 4 Top Networks, Functions, and Canonical Pathways from IPA analysis for Experiment 2

\begin{tabular}{|c|c|}
\hline Networks & Cancer, Cell Morphology, Dermatological Diseases and Conditions \\
\hline & Cell Signaling, DNA Replication, Recombination, and Repair, Nucleic Acid Metabolism \\
\hline & Cell Cycle, Embryonic Development, Connective Tissue Development and Function \\
\hline & Cancer, Reproductive System Disease, Hematological Disease \\
\hline \multirow[t]{5}{*}{ Functions } & Cellular Assembly and Organization \\
\hline & Cancer \\
\hline & Cellular Movement \\
\hline & Cell Cycle \\
\hline & Renal and Urological Disease \\
\hline \multirow[t]{5}{*}{ Canonical Pathways } & PI3K/AKT Signaling \\
\hline & One Carbon Pool by Folate \\
\hline & N-Glycan Degradation \\
\hline & Biosynthesis of Steroids \\
\hline & Urea Cycle and Metabolism of Amino Groups \\
\hline
\end{tabular}

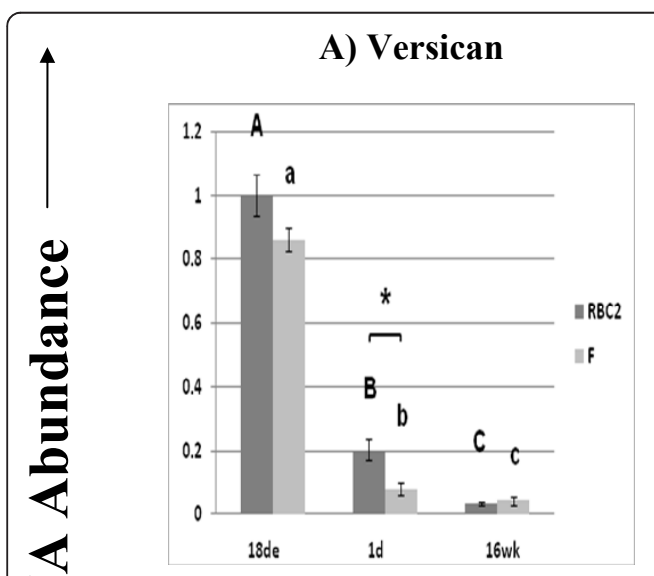

D) Spondin 2

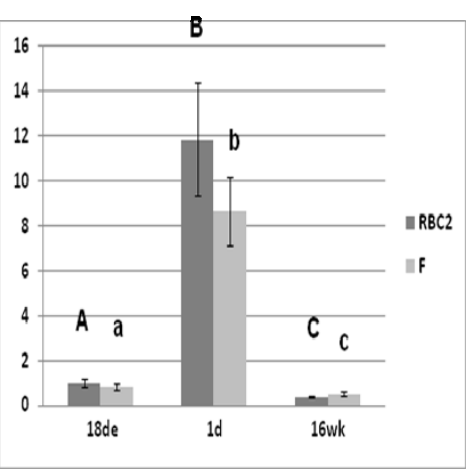

B) Glypican-1

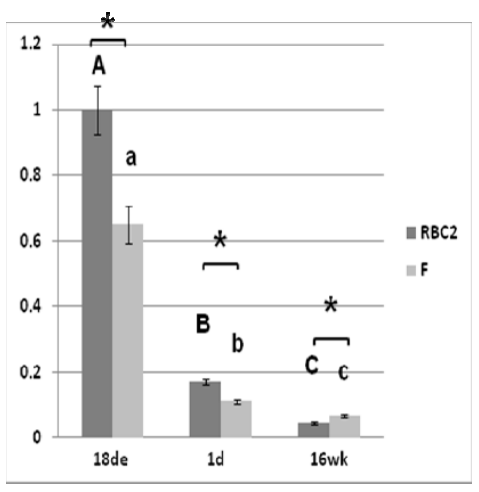

E) FGF2

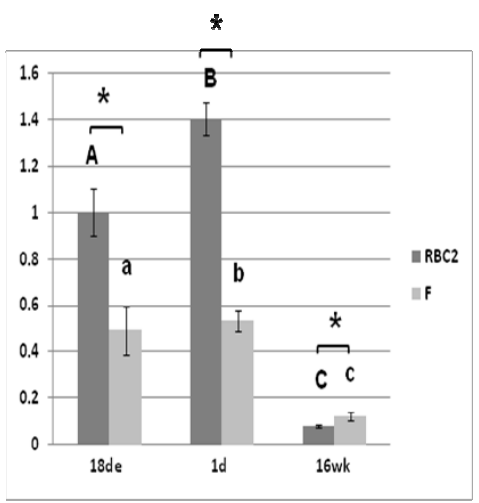

C) Syndecan-4

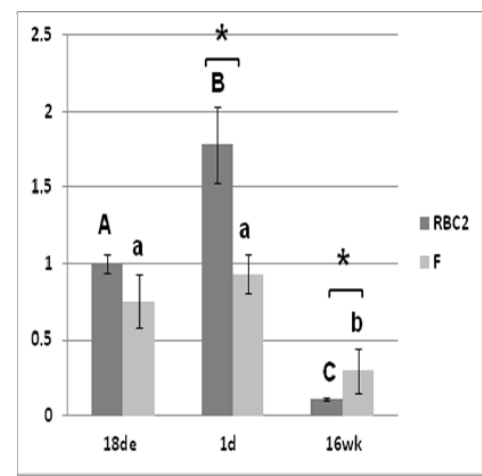

F) Collagen VI $\alpha 1$

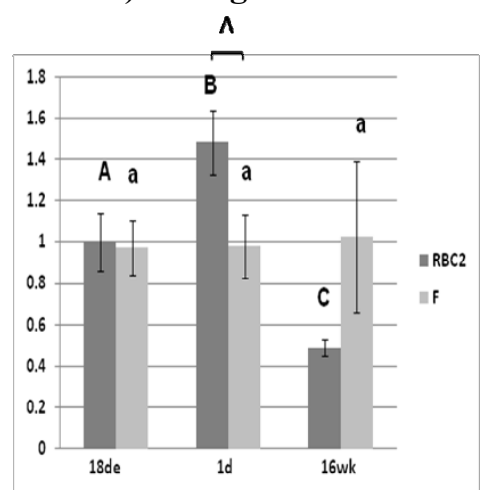

\section{Developmental Stage}

Figure 1 Relative expression as determined by quantitative real-time RT-PCR of genes related to extracellular matrix (ECM) function Different letters (uppercase) represent differences between developmental stages for the RBC2 line; different letters (lowercase) represent differences between developmental stages for the $F$ line $(P \leq 0.05)$. * represents differences between the two genetic lines, RBC2 and $F(P \leq$ $0.05) ; \wedge$ represents differences between the two lines $(0.05<P<0.10)$. 


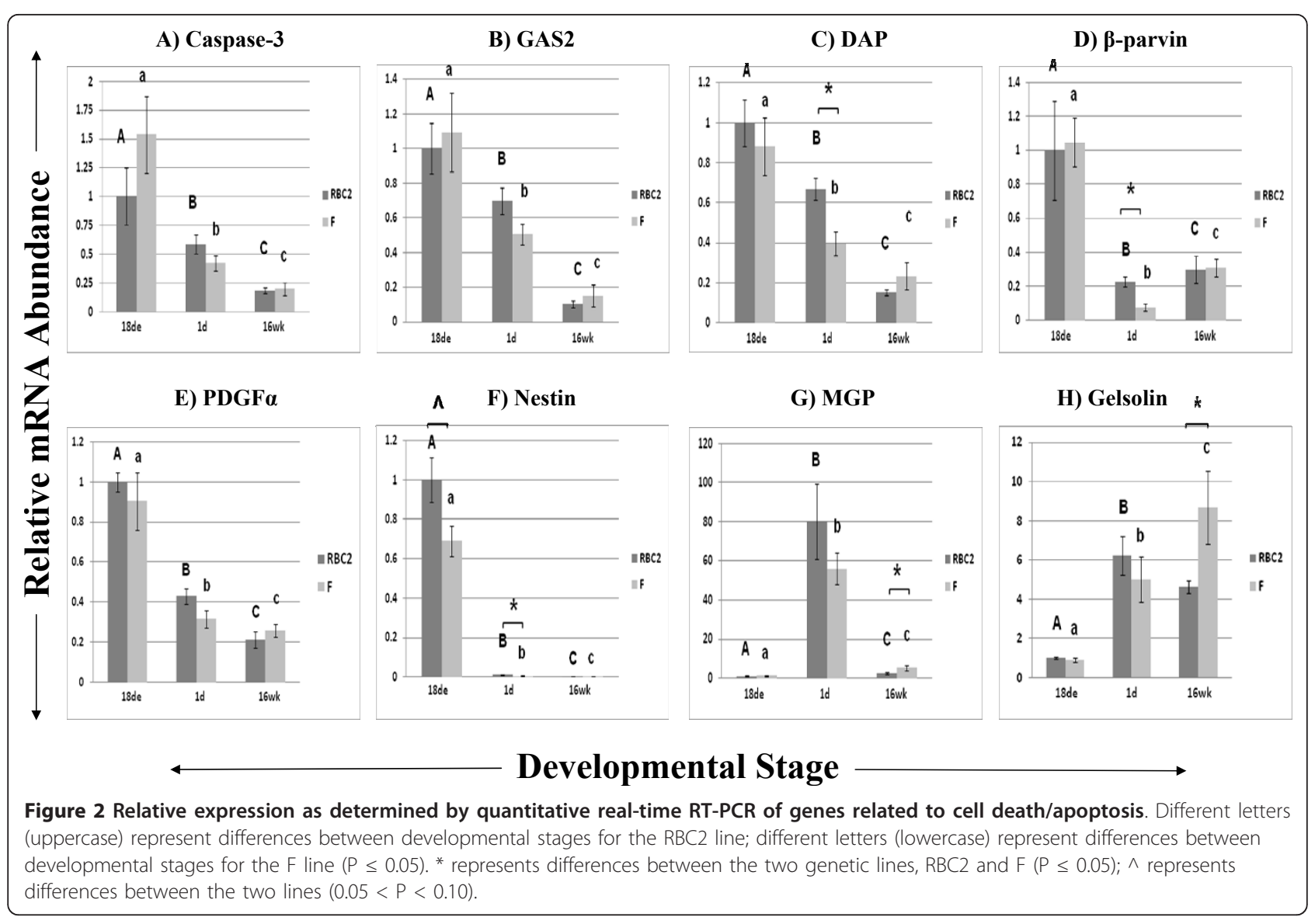

the pale, soft, and exudative (PSE) condition [31,32] and associated decreased meat protein functionality [33]. The goals in the current study were to exploit the capability of a microarray approach to identify functional pathways of genes and thus characterize molecular events associated with muscle development and between genetic lines of turkeys with different growth rates.

Obvious phenotypic differences exist between RBC2 birds and those from $\mathrm{F}$ or commercial lines. The $\mathrm{F}$ line turkeys gain body weight faster and yield significantly heavier breast muscles than the RBC2 birds [12]. In addition, satellite cells from the $F$ line have faster proliferation and differentiation rates than those from the $\mathrm{RBC} 2$ line [13]. Further, muscle damage with age is significant between lines as birds from the $\mathrm{F}$ line display a greater degree of muscle fiber fragmentation and areas of hypercontraction compared to those of the RBC2 [26]. These phenotypic differences are likely the results of differential gene expression throughout development.

This study identified over 3000 genes affected by developmental stage (Experiment 1), but only 16 genes were identified as being differentially expressed by overall effect of genetic line (Experiment 2). When considering effect of line within each developmental stage, the highest number of differences occurred early in development (18de stage). Expression changes in myogenic regulatory factor genes have previously been observed between the $\mathrm{F}$ and $\mathrm{RBC} 2$ lines at the embryonic stage [14], and satellite cells from F birds have been shown to have increased proliferation rates relative to $\mathrm{RBC} 2$ birds in vitro [13]. These results agree with the microarray observations and suggest that phenotypic differences between the two lines may largely be determined embryonically during myogenesis. It is possible that subtle differences in gene expression observed in the current study may be responsible for large phenotypic differences in body and breast muscle weight [12], breast muscle morphology [26], and meat quality characteristics [33] between the RBC2 and F lines at market age.

The Ingenuity Pathway Analysis (IPA) enabled the clustering of differentially expressed genes into functional categories, some of which were expected, while others were novel. Expected differences provided biological validation of the microarray approach, while the novel differences provided new paths to pursue in furthering our understanding of differences in turkey skeletal muscle growth and development. Many genes that may act as master regulators during development appeared in more 


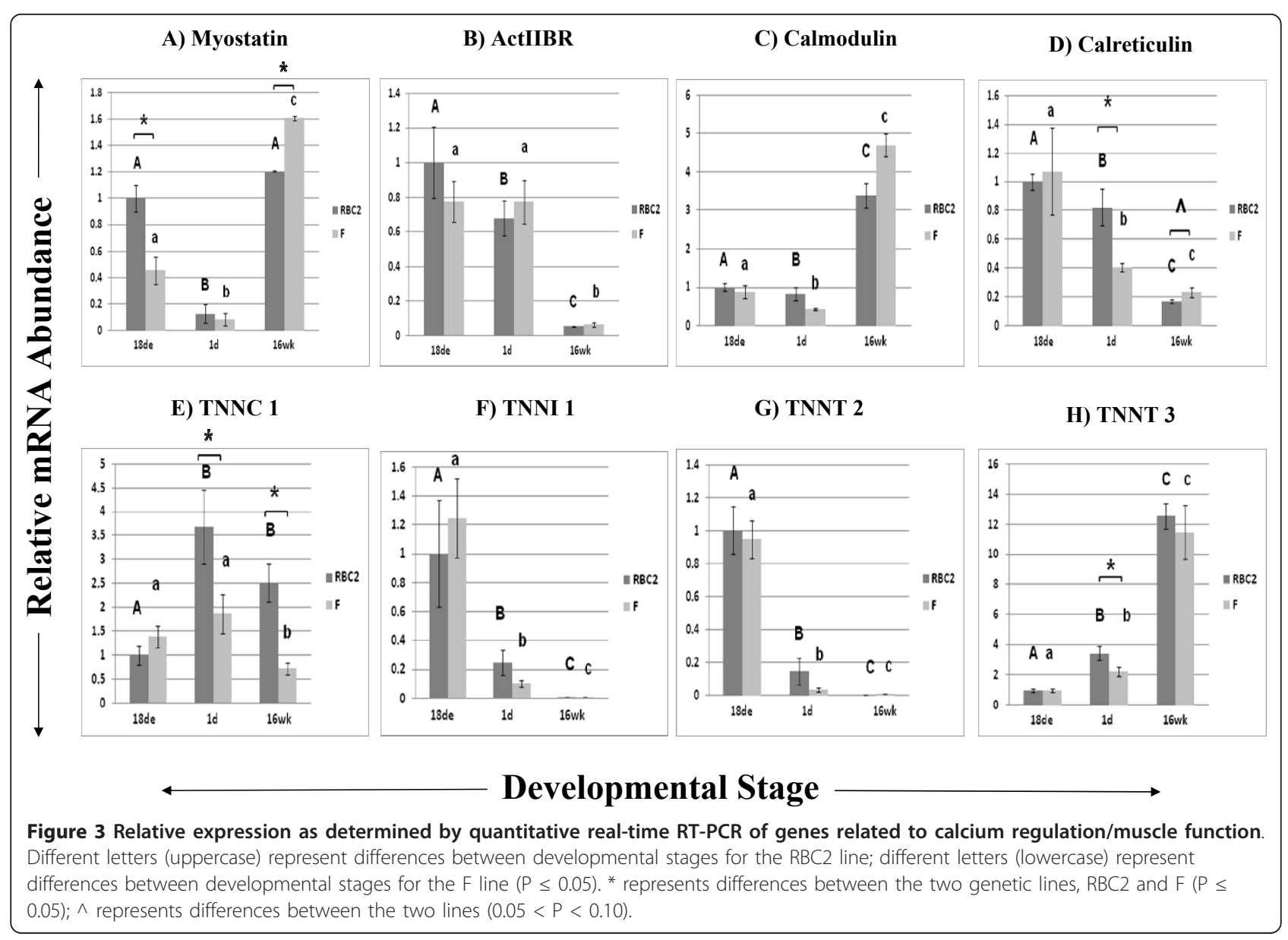

than one Network, Function, or Canonical Pathway. The identified gene expression differences were grouped by function and discussed, highlighting several individual genes of interest within each group.

\section{Extracellular Matrix Genes}

Previous studies have demonstrated that the ECM comprising the connective tissue surrounding muscle can interact with growth factors, regulate cellular signal transduction pathways, and affect growing and developing muscle fibers [34-36]. Genes that fell into numerous functions or canonical pathways as well as some genes that were not included in IPA networks were selected for this group. The ECM is composed mainly of collagens and nonfibrous glycoproteins like proteoglycans. The expression of three proteoglycans: versican, glypican-1, and syndecan-4, was quantified in this study. Membrane-associated proteoglycans in the ECM are known to regulate numerous growth factors, the major constituents that regulate activation, proliferation, and differentiation of satellite cells [8]. A predominant example is FGF2, a potent stimulator of muscle fiber proliferation and a strong inhibitor of differentiation [35,37]. This function would explain the high
FGF2 expression at 18de and 1d in the current study, as these are periods of myoblast or satellite cell proliferation. The interaction between FGF2 and the heparan sulfate proteoglycans glypican-1 and syndecan-4 is required for high-affinity binding of FGF2 to its cellular receptor [35]. Differences in expression of syndecan-4 have been observed in vitro between developing $\mathrm{RBC} 2$ and $\mathrm{F}$ line satellite cells [15], and RBC2 satellite cell expression of syndecan-4 as well as glypican-1 were altered with the addition of FGF2 [38]. Satellite cells from syndecan-4 knockout mice display defective patterns of activation, proliferation, and differentiation [39], indicating a crucial role in muscle development that is also supported for turkeys in the current study. In addition, syndecan-4 and FGF2 appear to have similar expression profiles, especially at $1 \mathrm{~d}$. Versican is a chondroitin sulfate proteoglycan that was expressed predominantly at the 18de stage in this study. Fernandez et al. (1991) hypothesized that this protein's high embryonic expression at the time of fiber formation may be involved in fiber spacing, establishing the morphological structure of the muscle in chicks [40]. The space between muscle fibers may play a critical role in the water-holding capacity of mature muscle and may 


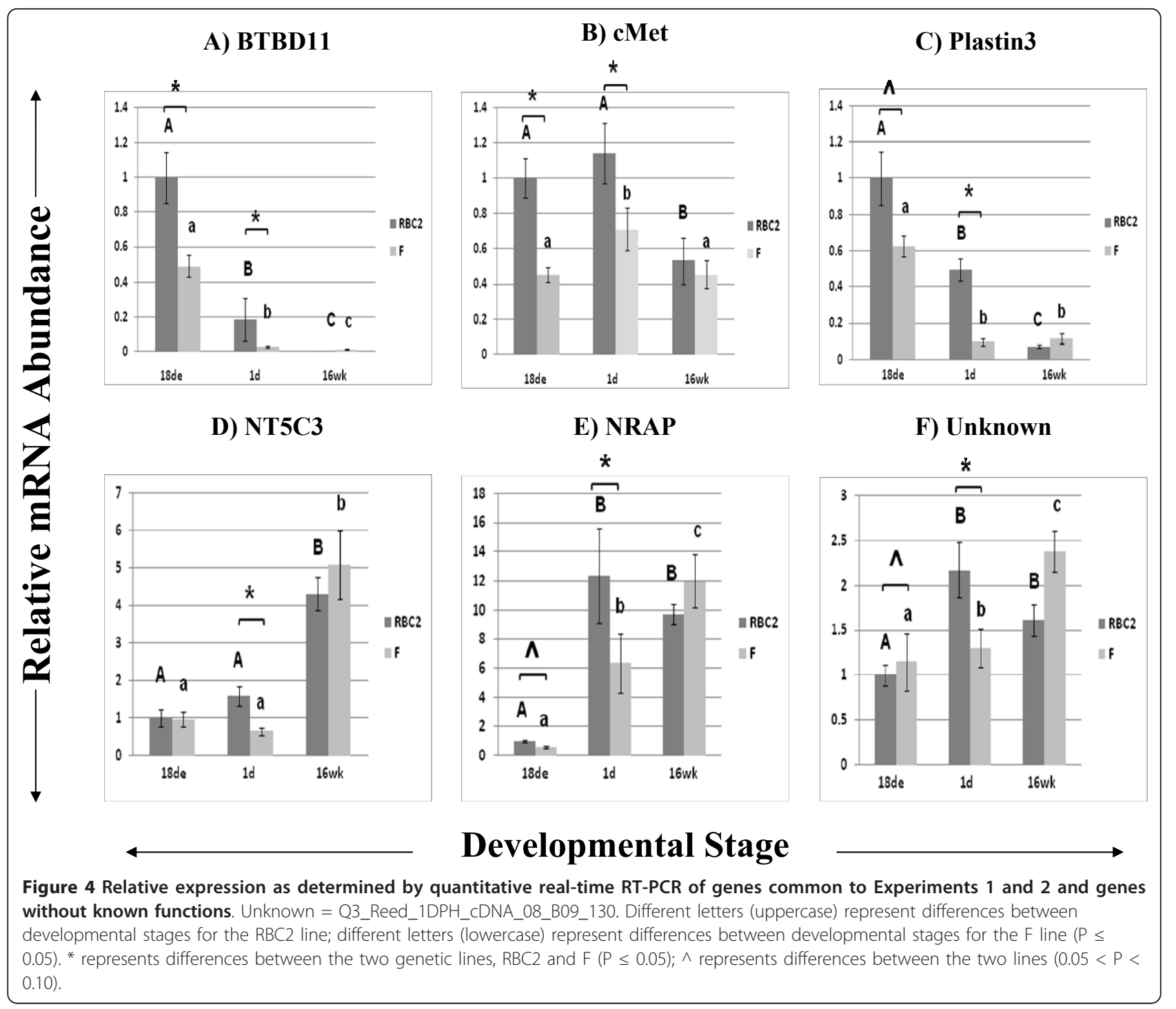

therefore be associated with quality defects like PSE meat. It is therefore possible that characteristics that contribute to meat quality are decided very early in myogenesis.

Dominant negative mutations in the COL6A1 gene, the only collagen that was investigated in the current study, are known to lead to Bethlem myopathy [41] and Ulrich congenital muscle dystrophy [42]; COL6A1 knockout mice exhibit sarcolemmal disorganization [43]. Taken together, it is clear that expression of genes whose proteins are located in the ECM of skeletal muscle likely contribute significantly to myogenesis in RBC2 and $\mathrm{F}$ turkeys.

\section{Cell Death/Apoptosis Genes}

Cell death and apoptosis are necessary events in muscle differentiation and maintenance. In addition, other reports have shown similarities between mechanisms of apoptosis and myoblast differentiation, suggesting that similar pathways and effectors may be in use $[44,45]$. Therefore, it was logical to further evaluate the expression of several differentially expressed genes associated with these functions. For example, caspase-3, an "executioner" cysteine protease in apoptosis [46], is necessary for proper differentiation of $\mathrm{C} 2 \mathrm{C} 12$ myoblasts [47]. However, several reports have shown that this role is separate from apoptosis $[44,45]$ although it employs similar mechanisms, such as DNA strand breakage [48].

A component of the microfilament, GAS2, is a substrate for caspase- 3 and is involved in microfilament reorganization, possibly an early event in apoptosis [49]. The protein is expressed in embryonic mouse limbs and involved in apoptosis during interdigital development; GAS2 may also be involved in myogenesis, possibly in the fusion of myoblasts to form myotubules [50]. In 
addition, GAS2 can regulate p53 action and apoptosis through its inhibition of calpain [51]. Nestin is the initial intermediate filament protein expressed during myogenesis [52-54], and phosphorylation of this protein is associated with the disassembly of intermediate filaments during mitosis [53]. Nestin is also associated with increased survival of rat vascular smooth muscle cells under stress [55]. Our results are in agreement as nestin is expressed predominantly at the 18de stage in turkey skeletal muscle when myoblasts are proliferating.

Another intriguing gene was DAP, which was expressed most highly at the 18de stage and decreased throughout development for both $\mathrm{RBC} 2$ and $\mathrm{F}$ birds. The human homologue of the gene was first identified in surviving HeLa cells treated with an antisense cDNA library and the cytokine interferon- $\gamma$ to induce apoptosis [56]. Very little is known about this gene other than it seemed to be a candidate for positive mediators of cell death [56,57] and that it may regulate autophagy in injured planarians [58] and in amino acid-starved HeLa cells [59]. In addition, DAP may play a role as a regulator of turkey skeletal muscle proliferation and differentiation as shown by our group's recent work with satellite cells in vitro (Vellemen et al., manuscript in preparation).

\section{$\mathrm{Ca}^{2+}$ Signaling/Muscle Function Genes}

The $\mathrm{Ca}^{2+}$ ion acts as a second messenger in cell signaling and in skeletal muscle contraction. Aberrant $\mathrm{Ca}^{2+}$ signaling postmortem likely plays an important role in the occurrence of meat quality defects that can lead to significant economic losses in the pork and poultry industries. During the postmortem conversion of muscle to meat, increased $\mathrm{Ca}^{2+}$ release from the sarcoplasmic reticulum while the muscle temperature is still high is thought to be responsible for skeletal muscle hypermetabolism that accelerates $\mathrm{pH}$ decline, leading to protein denaturation and loss of protein functionality [60,61]. A point mutation in the "halothane gene" or ryanodine receptor 1 (RYR1), the skeletal muscle sarcoplasmic reticulum $\mathrm{Ca}^{2+}$ release channel, has been identified in the pig [62] and has been associated with porcine stress syndrome (PSS), a sometimes fatal condition of malignant hyperthermia that is triggered by stress and is a major contributor to the development of PSE pork [60]. Genetic selection by pig breeders away from this mutation has not fully resolved the PSE problem. However, RYR1 became a logical candidate for examination in the turkey, a species that has been similarly selected for rapid lean muscle growth and also exhibits meat quality defects such as PSE. Further investigation of this protein in the turkey revealed a higher affinity for ryanodine in heavier commercial turkeys than those from the RBC2 line [63], suggesting a higher open-state probability of the $\mathrm{Ca}^{2+}$ release channel. Multiple alternatively spliced products were later discovered in the avian skeletal muscle ryanodine receptor isoform, $\alpha R Y R$, in $\mathrm{RBC} 2$ and commercial turkeys [64], and these alternative splicing sites are clustered in regions of the gene associated with increased frequency of mutations [65]. Recently, alternative splicing and changes in $\alpha R Y R$ expression have also been implicated in the occurrence of PSE meat in broiler chickens [66].

Several genes involved in $\mathrm{Ca}^{2+}$ metabolism were identified as differentially expressed during development in this study. Calreticulin functions as a $\mathrm{Ca}^{2+}$-binding chaperone and aids in maintaining $\mathrm{Ca}^{2+}$ homeostasis in the ER lumen of cells [67]. This protein also appears to be mainly expressed early in murine cardiac development and is essential for proper cardiac development [68]. Calmodulin is another $\mathrm{Ca}^{2+}$-binding protein that sensitizes RYR1 to activation at nanomolar concentrations of $\mathrm{Ca}^{2+}$ and inhibits RYR1 at micromolar concentrations [69]. However, more recent work suggests that calmodulin is not an essential regulator of RYR1 [70]. Nevertheless, calmodulin plays a central role in calcium signal transduction and the developmentally related changes in gene expression suggest a key role for this protein.

Myostatin is a highly-conserved transforming growth factor- $\beta$ (TGF- $\beta$ ) family member that strongly inhibits both hyperplasia and hypertrophy. Mutations or knockout of the gene result in an extreme increase in skeletal muscle mass in cattle and in mice [71]. In the current study, a dramatic decrease of myostatin expression was observed at $1 \mathrm{~d}$ post-hatch, which agrees with our understanding of myostatin function as myofibers are rapidly undergoing hypertrophy at this stage. In addition, line differences at 18de and 16 wk were observed, with $\mathrm{RBC} 2$ birds expressing myostatin significantly higher than $\mathrm{F}$ birds at $18 \mathrm{de}$. This result could imply that $\mathrm{F}$ birds are able to undergo a higher degree of hyperplasia and actually produce more mature muscle fibers, leading to greater muscle mass. At $16 \mathrm{wk}, \mathrm{F}$-line birds expressed significantly more myostatin, suggesting that the faster growth rate of the heavier birds plateaus sooner than the slower-growing $\mathrm{RBC} 2$-line birds. Activin receptor type IIB (ActIIBR) functions as a serine/ threonine kinase receptor for myostatin as well as other TGF- $\beta$ family members, and binding of these ligands to ActIIBR activates the Smad signal transduction pathway to regulate gene expression [72]. Inhibition of myostatin activity by construction of a dominant-negative ActRIIB lacking a kinase domain resulted in increased muscle hyperplasia and hypertrophy in mice, as well as competition with the TGF- $\beta$ family member follistatin [71]. Treatment of chicken fetal myoblasts with myostatin altered expression of genes involved in myogenic differentiation, cell architecture, energy metabolism, signal transduction and apoptosis [73], suggesting that increased myostatin 
expression in the current study could lead to similar changes.

Troponins are key proteins that are regulated by changes in intracellular $\mathrm{Ca}^{2+}$ concentrations and are responsible for striated muscle contraction. The three subunits of troponin interact with each other to bind $\mathrm{Ca}^{2+}$ (TNNC), inhibit myosin ATPase activity (TNNI), and to bind tropomyosin (TNNT) [74]. Transcript abundance of the fast/skeletal muscle isoform of TNNT, TNNT3, increased with development in the current study, peaking at $16 \mathrm{wk}$. Interestingly, the cardiac isoform, TNNT2, was chiefly expressed in the embryonic skeletal muscle, and its expression decreased during skeletal muscle development, which is consistent with previous findings in chicken [75,76]. Expression of another slow-twitch muscle/cardiac isoform of troponin, TNNI1, followed this pattern as well. The expression of all of the troponin isoforms is also in agreement with what is known about myofibrillar protein expression in rat skeletal muscle, as slow/cardiac forms are expressed during the development of myofibrils with a switch to fast/skeletal forms during postnatal growth and muscle regeneration [77]. These genes involved in muscle growth and $\mathrm{Ca}^{2+}$ signaling may be valuable candidates for changes observed in turkey skeletal muscle development.

\section{Miscellaneous/Genes of Unknown Function}

One of the goals of the current study was to identify novel genes with unknown or uncertain functions that may play important roles in skeletal muscle development. These genes may play important roles in myogenesis and development even though their annotations and functions have yet to be defined or may not have clear roles in skeletal muscle. In the current study, one gene without known annotation but identified as very highly differentially expressed by microarray analysis was chosen for further confirmation by qPCR along with others that did not easily fit into a functional category. These genes all showed line differences at $1 \mathrm{~d}$, indicating a possible important role during muscle hypertrophy that may help explain phenotypic differences between the slow-growing randombred line and the line selected for increased 16-wk body weight.

Several genes identified in this study were first discovered and their activities characterized in tissue types other than skeletal muscle. For example, spondin 2, (also known as mindin), which fell into the ECM group in our study, is expressed in spleen, lymph nodes, and dendritic cells and may be crucial to immune function [78]. In the current study, spondin 2 was expressed at highest levels at $1 \mathrm{~d}$ post-hatch, over 11 times higher than its 18de expression in both turkey lines. The MGP gene was first cloned in chickens and found in highest levels in bones and relatively low levels in skeletal muscle [79].
Previous studies indicate its role in the inhibition of vascular calcification, as MGP knockout mice die within 2 months due to blood vessel rupture [80]. It may also be important in intracellular calcium homeostasis [81]. While MGP was grouped into the "Cell Death" function by the IPA software, its association with apoptosis is not clear [81]. It was another gene that appeared to be "turned on" at $1 \mathrm{~d}$ post-hatch, with 80.28 and 55.38 times the 18de expression in $\mathrm{RBC} 2$ and $\mathrm{F}$ lines, respectively. Thus, this study has begun to uncover novel roles of these genes, which have been characterized in other tissues, in muscle growth and development.

Other interesting findings include the variation in the timing and extent of expression during development. A few stand-out genes were highly expressed at only one stage of development, clearly turned on or off in what appears to be carefully choreographed regulation. During the embryonic stage, when muscle cell hyperplasia is occurring, versican, glypican-1, betaparvin, nestin, TNNI1, and TNNT2 were expressed at least 5 times, and in the case of nestin greater than 100 times, higher than later developmental stages. Spondin 2 and MGP were both highly expressed at $1 \mathrm{~d}$ posthatch with very little expression at $18 \mathrm{de}$ or $16 \mathrm{wk}$. The NT5C 3 and TNNT3 genes peaked at $16 \mathrm{wk}$ of development.

\section{Conclusions}

Taken together, results from the current study demonstrated obvious differences in gene expression between three key developmental stages of turkey skeletal muscle growth. Although differences between the two genetic lines may be more subtle, the TSKMLO microarray platform proved useful in identifying candidate genes responsible for differences in muscle growth and opened the door for future experiments that focus on these candidate genes, their proteins, and their functions in turkey skeletal muscle.

\section{Additional material}

\footnotetext{
Additional File 1: Supplementary Figure 1 (Figure S1). Experimental designs of microarray experiments.

Additional File 2: Supplementary Table 1 (Table S1). Top thirty down-regulated and up-regulated genes in Experiment 1 in each of the following comparisons: RBC2 18de:1d, RBC2 1d: 16wk, F 18de: 1d, F $1 \mathrm{~d}: 16 \mathrm{wk}$, with fold changes, GenBank accession numbers, and putative annotations.

Additional File 3: Supplementary Table 2 (Table S2). Top downregulated and up-regulated genes (RBC2:F) in Experiment 2 for the developmental stages 18de, 1d, and 16wk with fold changes, GenBank accession numbers, and putative annotations.
}

\section{Acknowledgements}

We would like to gratefully acknowledge the assistance of Ms. Cindy Coy and Mr. Dennis Hartzler (sample collection and maintenance of turkey lines), 
Dr. Jeff Landgraf (array printing), Ms. Sue Sipkovsky (microarray technical assistance), Ms. Xiaoning Ren (RNA quality checks), and Dr. Hanem Hassan (RNA extraction). This project was supported by National Research Initiative Competitive Grant no. 2005-35604-15628 from the USDA National Institute of Food and Agriculture to G.M.S., C.W.E., K.M.R., S.G.V., and R.J.T.

\section{Author details}

'Department of Food Science and Human Nutrition, Michigan State University, East Lansing, Michigan, 48824, USA. ${ }^{2}$ Department of Animal Science, Michigan State University, East Lansing, Michigan, 48824, USA. ${ }^{3}$ Department of Veterinary and Biomedical Sciences, University of Minnesota, St. Paul, Minnesota, 55108, USA. ${ }^{4}$ Department of Animal Sciences, The Ohio State University/Ohio Agricultural Research and Development Center, Wooster, Ohio, 44691, USA.

\section{Authors' contributions}

KRBS carried out all microarray and $\mathrm{qPCR}$ procedures, annotation and pathway analysis, and wrote the manuscript. RJT was involved in experimental design and statistically analyzed all microarray data. CWE, KMR, SGV, and GMS were involved in experimental design and drafting the manuscript. All authors read and approved the final manuscript.

Received: 29 September 2010 Accepted: 8 March 2011

Published: 8 March 2011

\section{References}

1. Smith JH: Relation of body size to muscle cell size and number in the chicken. Poult Sci 1963, 42:283-290.

2. Velleman SG: Muscle development in the embryo and hatchling. Poult SCi 2007, 86:1050-1054.

3. Moss FP: The relationship between the dimensions of the fibres and the number of nuclei during normal growth of skeletal muscle in the domestic fowl. Am J Anat 1968, 12:555-564.

4. Relaix F, Montarras D, Zaffran S, Gayraud-Morel B, Rocancourt D, Tajbakhsh S, Mansouri A, Cumano A, Buckingham M: Pax3 and Pax7 have distinct and overlapping functions in adult muscle progenitor cells. J Cell Biol 2006, 172(1):91-102.

5. Buckingham M, Relaix F: The role of Pax genes in the development of tissues and organs: Pax3 and Pax7 regulate muscle progenitor cell functions. Annu Rev Cell Dev Biol 2007, 23:645-673.

6. Ludolph DC, Konieczny SF: Transcription factor families: muscling in on the myogenic program. FASEB J 1995, 9(15):1595-1604.

7. Olson EN, Perry M, Schulz RA: Regulation of muscle differentiation by the MEF2 family of MADS box transcription factors. Dev Biol 1995, 172(1):2-14.

8. McFarland DC: Influence of growth factors on poultry myogenic satellite cells. Poult Sci 1999, 78(5):747-758.

9. McFarland DC, Pesall JE, Gilkerson KK, Ferrin NH: The response to growth factors of cultured satellite cells derived from turkeys having different growth rates. Cytobios 1995, 82(331):229-238.

10. Nestor KE, McCartney MG, Bachev N: Relative contributions of genetics and environment to turkey improvement. Poult Sci 1969, 48:1944-1949.

11. Nestor KE: Genetics of growth and reproduction in the turkey. 9. Longterm selection for increased 16-week body weight. Poult Sci 1984, 63:2114-2122.

12. Lilburn MS, Nestor KE: Body weight and carcass development in different lines of turkeys. Poult Sci 1991, 70:2223-2231.

13. Velleman SG, Liu X, Nestor KE, McFarland DC: Heterogeneity in growth and differentiation characteristics in male and female satellite cells isolated from turkey lines with different growth rates. Comp Biochem Physiol A Mol Integr Physiol 2000, 125(4):503-509.

14. Liu C, McFarland DC, Velleman SG: Effect of genetic selection on MyoD and myogenin expression in turkeys with different growth rates. Poult Sci 2005, 84(3):376-384

15. Liu C, MCFarland DC, Nestor KE, Velleman SG: Differential expression of membrane-associated heparan sulfate proteoglycans in the skeletal muscle of turkeys with different growth rates. Poult Sci 2006, 85:422-428.

16. Liu X, McFarland DC, Nestor KE, Velleman SG: Developmental regulated expression of syndecan-1 and glypican in pectoralis major muscle in turkeys with different growth rates. Dev Growth Diff 2004, 46:37-51.
17. Sporer KR, Chiang W, Tempelman RJ, Ernst CW, Reed KM, Velleman SG, Strasburg GM: Characterization of a $6 \mathrm{~K}$ oligonucleotide turkey skeletal muscle microarray. Anim Genet 2011, 42(1):75-82.

18. Reed KM, Mendoza KM, Juneja B, Fahrenkrug SC, Velleman S, Chiang W, Strasburg GM: Characterization of expressed sequence tags from turkey skeletal muscle. Anim Genet 2008, 39(6):635-644.

19. Nestor KE: The stability of two randombred control populations of turkeys. Poult Sci 1977, 56:54-57.

20. Kerr KF, Serikawa KA, Wei C, Peters MA, Bumgarner RE: What is the best reference RNA? And other questions regarding the design and analysis of two-color microarray experiments. OMICS 2007, 11(2):152-165.

21. Allison DB, Cui X, Page GP, Sabripour M: Microarray data analysis: from disarray to consolidation and consensus. Nat Rev Genet 2006, 7(1):55-65.

22. Smyth GK: Linear models and empirical Bayes methods for assessing differential expression in microarray experiments. Stat App Genet Mol Biol 2004, 3(1), Article 3.

23. Wolfinger RD, Gibson $G$, Wolfinger ED, Bennett $L$, Hamadeh $H$, Bushel $P$, Afshari C, Paules RS: Assessing gene significance from CDNA microarray expression data via mixed models. J Comput Biol 2001, 8(6):625-637.

24. Storey JD, Tibshirani R: Statistical methods for identifying differentially expressed genes in DNA microarrays. Methods Mol Biol 2003, 224:149-157.

25. Livak KJ, Schmittgen TD: Analysis of relative gene expression data using real-time quantitative PCR and the $2^{-\delta \delta C t}$ method. Methods 2001, 25:402-408.

26. Velleman SG, Anderson JW, Coy CS, Nestor KE: Effect of selection for growth rate on muscle damage during turkey breast muscle development. Poult Sci 2003, 82:1069-1074.

27. Wilson BW, Nieberg PS, Buhr RJ, Kelly BJ, Shultz FT: Turkey muscle growth and focal myopathy. Poult Sci 1990, 69(9):1553-1562.

28. Czarnecki CM: Cardiomyopathy in turkeys. Comp Biochem Phys 1984, 77A(4):591-598.

29. Stenzel T, Tykalowski B, Koncicki A: Cardiovascular system diseases in turkeys. Pol J Vet Sci 2008, 11(3):245-250.

30. Julian RJ: Rapid growth problems: ascites and skeletal deformities in broilers. Poult Sci 1998, 77:1773-1780.

31. Owens CM, Hirschler EM, McKee SR, Martinez-Dawson R, Sams AR: The characterization and incidence of pale, soft, exudative turkey meat in a commercial plant. Poult Sci 2000, 79:553-558.

32. Dransfield E, Sosnicki AA: Relationship between muscle growth and poultry meat quality. Poult Sci 1999, 78:743-746.

33. Updike MS, Zerby HN, Sawdy JC, Lilburn MS, Kaletunc G, Wick MP: Turkey breast meat functionality differences among turkeys selected for body weight and/or breast yield. Meat Sci 2005, 71:706-712.

34. Jenniskens $G J$, Veerkamp JH, van Kuppevelt TH: Heparan sulfates in skeletal muscle development and physiology. J Cell Physiol 2006, 206(2):283-294.

35. Velleman SG: Role of the extracellular matrix in muscle growth and development. J Anim Sci 2002, 80(E Suppl 2):E8-E13.

36. Velleman SG, Liu X, Eggen KH, Nestor KE: Developmental regulation of proteoglycan synthesis and decorin expression during turkey embryonic skeletal muscle formation. Poult Sci 1999, 78(11):1619-1626.

37. Velleman SG: The role of the extracellular matrix in skeletal muscle development. Poult Sci 1999, 78:778-784.

38. Velleman SG, Li X, Coy CS, McFarland DC: The effect of fibroblast growth factor 2 on the in vitro expression of syndecan-4 and glypican- 1 in turkey satellite cells. Poult Sci 2008, 87:1834-1840.

39. Cornelison DD, Wilcox-Adelman SA, Goetinck PF, Rauvala H, Rapraeger AC, Olwin BB: Essential and separable roles for Syndecan-3 and Syndecan-4 in skeletal muscle development and regeneration. Genes Dev 2004, 18(18):2231-2236.

40. Fernandez MS, Dennis JE, Drushel RF, Carrino DA, Kimata K, Yamagata M, Caplan Al: The dynamics of compartmentalization of embryonic muscle by extracellular matrix molecules. Dev Biol 1991, 147(1):46-61.

41. Jobsis GJ, Boers JM, Barth PG, de Visser M: Bethlem myopathy: a slowly progressive congenital muscular dystrophy with contractures. Brain 1999, 122(Pt 4):649-655.

42. Camacho Vanegas O, Bertini E, Zhang RZ, Petrini S, Minosse C, Sabatelli P, Giusti B, Chu ML, Pepe G: Ullrich scleroatonic muscular dystrophy is caused by recessive mutations in collagen type VI. Proc Natl Acad Sci USA 2001, 98(13):7516-7521. 
43. Canato M, Dal Maschio M, Sbrana F, Raiteri R, Reggiani C, Vassanelli S, Megighian A: Mechanical and electrophysiological properties of the sarcolemma of muscle fibers in two murine models of muscle dystrophy: col6a1-/- and mdx. J Biomed Biotechnol 2010, 2010:981945.

44. Ikeda T, Kanazawa T, Otsuka S, Ichii O, Hashimoto Y, Kon Y: Expression of caspase family and muscle- and apoptosis-specific genes during skeletal myogenesis in mouse embryo. J Vet Med Sci 2009, 71(9):1161-1168.

45. Murray TV, McMahon JM, Howley BA, Stanley A, Ritter T, Mohr A, Zwacka R, Fearnhead HO: A non-apoptotic role for caspase-9 in muscle differentiation. J Cell Sci 2008, 121(Pt 22):3786-3793.

46. Slee EA, Adrain C, Martin SJ: Executioner caspase-3, -6, and -7 perform distinct, non-redundant roles during the demolition phase of apoptosis. J Biol Chem 2001, 276(10):7320-7326.

47. Fernando P, Kelly JF, Balazsi K, Slack RS, Megeney LA: Caspase 3 activity is required for skeletal muscle differentiation. Proc Natl Acad Sci USA 2002, 99(17):11025-11030

48. Larsen BD, Rampalli S, Burns LE, Brunette S, Dilworth FJ, Megeney LA: Caspase 3/caspase-activated DNase promote cell differentiation by inducing DNA strand breaks. Proc Natl Acad Sci USA 2010, 107(9):4230-4235.

49. Sgorbissa A, Benetti R, Marzinotto S, Schneider C, Brancolini C: Caspase-3 and caspase- 7 but not caspase- 6 cleave Gas2 in vitro: implications for microfilament reorganization during apoptosis. J Cell Sci 1999, 112((Pt 23)):4475-4482.

50. Lee KK, Tang MK, Yew DT, Chow PH, Yee SP, Schneider C, Brancolini C: gas2 is a multifunctional gene involved in the regulation of apoptosis and chondrogenesis in the developing mouse limb. Dev Biol 1999, 207(1):14-25.

51. Benetti R, Del Sal G, Monte M, Paroni G, Brancolini C, Schneider C: The death substrate Gas2 binds $\mathrm{m}$-calpain and increases susceptibility to p53-dependent apoptosis. EMBO J 2001, 20(11):2702-2714.

52. Sejersen $T$, Lendahl U: Transient expression of the intermediate filmament nestin during skeletal muscle development. J Cell Sci 1993, 106:1291-1300.

53. Michalczyk K, Ziman M: Nestin structure and predicted function in cellular cytoskeletal organisation. Histol Histopathol 2005, 20:665-671.

54. Kachinsky AM, Dominov JA, Miller JB: Myogenesis and the intermediate filament protein, nestin. Dev Biol 1994, 165(1):216-228.

55. Huang YL, Wu CM, Shi GY, Wu GC, Lee H, Jiang MJ, Wu HL, Yang HY: Nestin serves as a prosurvival determinant that is linked to the cytoprotective effect of epidermal growth factor in rat vascular smooth muscle cells. J Biochem 2009, 146(3):307-315.

56. Deiss LP, Feinstein E, Berissi $H$, Cohen $O$, Kimchi $A$ : Identification of a novel serine/threonine kinase and a novel $15-k D$ protein as potential mediators of the gamma interferon-induced cell death. Genes Dev 1995 9(1):15-30.

57. Levy-Strumpf N, Kimchi A: Death associated proteins (DAPs): from gene identification to the analysis of their apoptotic and tumor suppressive functions. Oncogene 1998, 17(25):3331-3340.

58. Gonzalez-Estevez C, Felix DA, Aboobaker AA, Salo E: Gtdap-1 promotes autophagy and is required for planarian remodeling during regeneration and starvation. Proc Natl Acad Sci USA 2007, 104(33):13373-13378.

59. Koren I, Reem E, Kimchi A: DAP1, a novel substrate of mTOR, negatively regulates autophagy. Curr Biol 2010, 20(12):1093-1098.

60. Barbut S, Sosnicki AA, Lonergan SM, Knapp T, Ciobanu DC, Gatcliffe LJ, HuffLonergan E, Wilson EW: Progress in reducing the pale, soft and exudative (PSE) problem in pork and poultry meat. Meat Science 2008, 79:46-63.

61. Strasburg GM, Chiang W: Pale, soft, exudative turkey - The role of ryanodine receptor variation in meat quality. Poultry Science 2009, 88:1497-1505.

62. Fujii J, Otsu K, Zorzato F, de Leon S, Khanna VK, Weiler JE, O'Brien PJ, MacLennan DH: Identification of a mutation in porcine ryanodine receptor associated with malignant hyperthermia. Science 1991, 253:448-451.

63. Wang LJ, Byrem TM, Zarosley J, Booren AM, Strasburg GM: Skeletal muscle calcium channel ryanodine binding activity in genetically unimproved and commercial turkey populations. Poult Sci 1999, 78:792-797.

64. Chiang W, Allison CP, Linz JE, Strasburg GM: Identification of two aRYR alleles and characterization of aRYR transcript variants in turkey skeletal muscle. Gene 2004, 330:177-184.
65. Chiang W, Yoon HJ, Linz JE, Airey JA, Strasburg GM: Divergent mechanisms in generating molecular variations of aRYR and $\beta R Y R$ in turkey skeletal muscle. J Muscle Res Cell Motil 2007, 28(6):343-354.

66. Ziober IL, Paiao FG, Marchi DF, Coutinho LL, Binneck E, Nepomuceno AL, Shimokomaki M: Heat and chemical stress modulate the expression of the alpha-RYR gene in broiler chickens. Genet Mol Res 2010, 9(2):1258-1266.

67. Michalak M, Corbett EF, Mesaeli N, Nakamura K, Opas M: Calreticulin: one protein, one gene, many functions. Biochem J 1999, 344(Pt 2):281-292.

68. Mesaeli N, Nakamura K, Zvaritch E, Dickie P, Dziak E, Krause KH, Opas M, MacLennan DH, Michalak M: Calreticulin is essential for cardiac development. J Cell Biol 1999, 144(5):857-868.

69. Rodney GG, Williams BY, Strasburg GM, Beckingham K, Hamilton SR: Regulation of RYR1 activity by $\mathrm{Ca}^{2+}$ and calmodulin. Biochem 2000, 39:7807-7812.

70. Rodney GG: Calmodulin in adult mammalian skeletal muscle: localization and effect on sarcoplasmic reticulum Ca2+ release. Am J Physiol Cell Physiol 2008, 294(5):C1288-1297.

71. Lee SJ, MCPherron AC: Regulation of myostatin activity and muscle growth. Proc Natl Acad Sci USA 2001, 98(16):9306-9311.

72. Tsuchida K, Nakatani M, Uezumi A, Murakami T, Cui X: Signal transduction pathway through activin receptors as a therapeutic target of musculoskeletal diseases and cancer. Endocr J 2008, 55(1):11-21.

73. Yang W, Zhang Y, Ma G, Zhao X, Chen Y, Zhu D: Identification of gene expression modifications in myostatin-stimulated myoblasts. Biochem Biophys Res Comm 2005, 326:660-666.

74. Gomes AV, Potter JD, Szczesna-Cordary D: The role of troponins in muscle contraction. IUBMB Life 2002, 54:323-333.

75. Toyota N, Shimada Y: Differentiation of troponin in cardiac and skeletal muscles in chicken embryos as studied by immunofluorescence microscopy. J Cell Biol 1981, 91(2 Pt 1):497-504.

76. Ogasawara $Y$, Komiya T, Obinata T: Identification of two variants of troponin $\mathrm{T}$ in the developing chicken heart using a monoclonal antibody. J Biochem 1987, 102(1):25-30.

77. Schiaffino S, Reggiani C: Molecular diversity of myofibrillar proteins: gene regulation and functional significance. Physiol Rev 1996, 76(2):371-423.

78. Li Y, Cao C, Jia W, Yu L, Mo M, Wang Q, Huang Y, Lim JM, Ishihara M, Wells $L$, et al: Structure of the F-spondin domain of mindin, an integrin ligand and pattern recognition molecule. EMBO J 2009, 28(3):286-297.

79. Wiedemann M, Trueb B, Belluoccio D: Molecular cloning of avian matrix Gla protein. Biochim Biophys Acta 1998, 1395(1):47-49.

80. Luo G, Ducy P, McKee MD, Pinero GJ, Loyer E, Behringer RR, Karsenty G: Spontaneous calcification of arteries and cartilage in mice lacking matrix GLA protein. Nature 1997, 386(6620):78-81.

81. Proudfoot D, Shanahan CM: Molecular mechanisms mediating vascular calcification: role of matrix Gla protein. Nephrol 2006, 11(5):455-461.

doi:10.1186/1471-2164-12-143

Cite this article as: Sporer et al:: Transcriptional profiling identifies differentially expressed genes in developing turkey skeletal muscle. BMC Genomics 2011 12:143.

\section{Submit your next manuscript to BioMed Central and take full advantage of:}

- Convenient online submission

- Thorough peer review

- No space constraints or color figure charges

- Immediate publication on acceptance

- Inclusion in PubMed, CAS, Scopus and Google Scholar

- Research which is freely available for redistribution

Submit your manuscript at www.biomedcentral.com/submit
C Biomed Central 